\title{
An Examination of Abroad Experienced Students' Coping Strategies
}

\author{
Leyla Esentürk-Ercan \\ Gazi University, Gazi Faculty of Education Department of Psychological Counseling Ankara Turkey. \\ Email:leyla62@gmail.com Tel: +905053197295
}

\section{Abstract}

The aim of the study was to analyse the problems of abroad experienced university students after returning to Turkey and the coping strategy that they use for these problems have been examined according to the factors such as gender, age and duration of the abroad experience. The participants were 102 abroad experienced students ( 45 female; 57 male); studying in a university in Ankara Turkey who participated in the study as volunteers. To collect data; Personel Information Form and Coping Questionnaire (Aysan, 2003) were used. Analysis of data by the independent saples t-test, one way analysis of variance (ANOVA) technique was used. Analizing data is made on computer. The results of the study are that abroad experienced students, who returned to Turkey from abroad, have problems of academic success, problems with their families and friends and problems of future life. The findings show that the length of the abroad life has a determining role on the selection of the coping strategies adapted by them.

Keywords: Return migration, Problems, Coping, Coping strategies, Counseling, Turkish migrants.

Citation | Leyla Esentürk-Ercan (2020). An Examination of Abroad Experienced Students' Coping Strategies. Asian Journal of Education and Training, 6(4): 602-607.

History:

Received: 5 August 2020

Revised: 9 September 2020

Accepted: 25 September 2020

Published: 7 October 2020

Licensed: This work is licensed under a Creative Commons

Attribution 3.0 License (cc) EY

Publisher: Asian Online Journal Publishing Group
Funding: This study received no specific financial support

Competing Interests: The author declares that there are no conflicts of interests regarding the publication of this paper.

Transparency: The author confirms that the manuscript is an honest, accurate, and transparent account of the study was reported; that no vital features of the study have been omitted; and that any discrepancies from the study as planned have been explained.

Ethical: This study follows all ethical practices during writing.

\section{Contents}

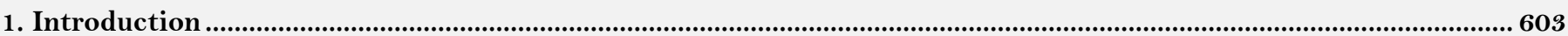

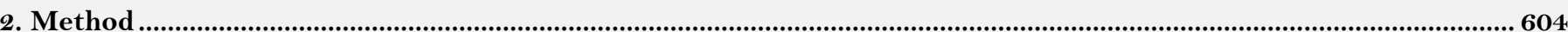

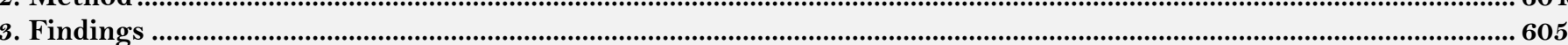

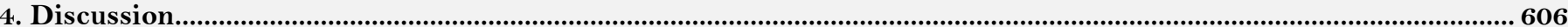

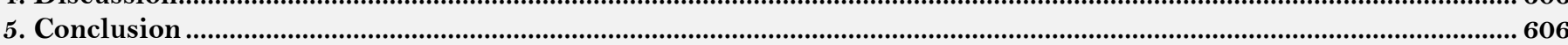

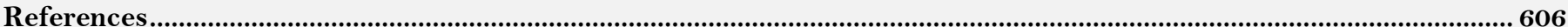




\section{Contribution of this paper to the literature}

This paper contributes to the existing literature by examining abroad experienced students' coping strategies. This study was researched because the number of studies investigating the problems and coping strategies of return migration of the abroad experienced Turkish students was insufficient.

\section{Introduction}

Work migration from Turkey to Germany started in the early 1960s (Razum, Sahin-Hodoglugil, \& Polit, 2005).Effecting date of "The Exchange Agreement for Turkish and German Workers" dated October 31, 1961, which was signed with the Government of Federal Germany, is generally accepted as the starting time when large groups of Turkish workers went to the countries in Western Europe to work. This bilateral agreement signed with Germany was followed by many agreements, which were signed to regulate the terms for the exchange with various countries. Among them were the agreement with Austria, Belgium and Holland in 1964, the agreement with France in 1965 and those with Australia and Sweden in 1967 (Cetïn \& Ercan, 2008; Doğan, 1988).

In the 1960 s and 1970s, hundreds of thousands of Turkish workers migrated to Germany. Some settled there, others returned to Turkey after a few years. As of 1982 the countries that demanded labor encouraged the Turkish workers to return to Turkey. In 1983, the German government offered financial incentives for a return to Turkey, and the Turkish population in Germany declined, albeit only temporarily (Razum et al., 2005).

In recent years, Turkish workers have had a tendency to return to Turkey and have started to send their children for education in Turkey (Cetïn \& Ercan, 2008; Sahin, 2001; Yasa, 1979).

Return was rarely based on purely economic or health-related motives; value-oriented and emotional themes almost always played a role (Razum et al., 2005).

Their return that started as of 1973 tended to increase over years and it reached its peak in 1983-1990, many people returned to Turkey. Returns are continuing although their rate is not as high as that of 1983-1990 (Cetin \& Ercan, 2008).

Return migration remains a dynamic process: every year, about 40.000 Turks return from Germany to Turkey; unfortunately, there is not exact information as to the number of people who have returned to Turkey up to now (Federal Statistical Office, 2001).

As these immigrants are a group that is difficult to trace and contact, little is known about their actual reasons for return (Razum et al., 2005).

In the last years, returns have tended to increase, families most of the times do not confer with their children before returning to Turkey, and they believe that it is to their advantage. On the other hand, it is suggested that the youngsters who are forced to return to Turkey have a resistance not to leave their familiar environment, which results in intra-family conflicts, escaping from the house even committing a suicide. Teacher - student relations, disciplinary understanding and practices in the countries in which they lived before are quite different from those in Turkey. Some of these children were born and raised in a foreign country; some of them were born in Turkey and went abroad to their families at their school ages or the age about it. It is expected that the type of the difference may lead to problems and adaptation difficulties (Doğan, 1988; Esentürk-Ercan, 2004).

The researches carried out in Turkey about the students who returned from abroad suggest that they have adaptation problems, problems with their families and friends, problems of academic success, depression, anxiety and the like (Doğan, 1988; Esentürk-Ercan, 2004; Kuruuzüm, 2002).

Research findings about return migration show that the longer one remains in the host culture, the more difficult the reentry process will be (Bennett, McKnight, \& Passin, 1958; Esentürk-Ercan, 2004).

For the students who have adapted themselves to the education system of the country in which they live, adapted some values and norms of that society the returning means a new migration. Therefore they have to cope with the problems again that they experienced when they first went abroad (Cetïn \& Ercan, 2008; Esentürk-Ercan, 2004; Kuruuzüm, 2002).

Specialists use the term "discordant" for the youngsters who do not integrate themselves to the European culture and become alienated gradually in their own country and point out that they are subject to the risk for their psychological health (Esentürk-Ercan, 2004).

According to some inter-cultural studies carried out on this subject the "Returning" is far more difficult than going to a foreign country and entails a longer adaptation period. The cultural shock is accepted as normal while the returning shock is generally not recognized. Culture shock, as a phenomenom, is well documented in the literature (Esentürk-Ercan, 2004; Sahin, 2001).

However relatively little research has been done on cultural shock resulting from reentry into one's home country following a sojourn abroad (Christofi \& Thompson, 2007).

Seiffge-Krenke (1990) compared the coping styles of 353 German and 187 Israeli adolescents, aged 15-17 years. The results of the study show, coping behavior among German adolescents was more influenced by situational demands, with pronounced approach-avoidance behavior. The Israeli adolescents showed less variability in coping behavior across situations, laid greater stress on cognitive factors, and showed a striking decrease in overall coping behavior with increasing age.

The results of Gama and Pedersen (1977) show that Brazilian women had more reentry problems than Brazilian men did after living in the United States.

The findings of an another study show that women were significantly more satisfied than men upon return to their home culture (Rohrlich \& Martin, 1991).

Christofi and Thompson (2007) investigated the structure of the experience of people who returned home after studying abroad, results of the study show that they became disillusioned with their home country and returned to their sojourn country.

Gullahorn and Gullahorn (1963) reported that older returnees had less difficulty readjusting than did younger returnees. Gullahorn and Gullahorn also found that students who returned from Europe faced less dissatisfaction 
on their return home than did those who sojourned in countries very different from their home (cited in Christofi and Thompson (2007)).

Martin (1984) found that relationships with friends were affected negatively, which influenced reentry adjustment. In addition, research supports the hypothesis that individuals who adapt most successfully overseas have a more severe reentry adjustment problem than those individuals who do not adapt overseas (Brein\& David, 1971; Brislin, 1981; Hara, 1984; LaBrack, 1983; Smith, 1975; cited in Christofi and Thompson (2007)).

Mudra (2008) investigated "A Study of Perceived Stress, Impact and Coping Strategies" in India with the purpose to investigate stress sources, it's impact and coping strategies in rural youth. Findings showed that males were using above said coping strategies more frequently than females. Similarly stress was divided into seven subclasses based on the type of problems faced by responds i.e. work related stress, family related stress, relationship related stress, financial stress, personal stress, bereavement stress, migration stress.

Tam and Lam (2005) compared stress and coping among 243 migrant and 750 local-born Chinese adolescents in Hong Kong. Findings showed that compared to their local-born counterparts, migrants showed no difference in perceived stress, whereas they were less likely to use withdrawal coping and showed higher self-esteem and less delinquent behavior. Adjustment of migrant adolescents was related to the father's education level and years of residence in Hong Kong.

Kung, Castaneda, and Lee (2004) analyzed a sample of 159 Americans from low socio-economic stratum, the immigrants $(\mathrm{N}=84)$ showed a slightly lower depression level, though statistically nonsignificant, when compared with the native born $(\mathrm{N}=75)$. The immigrants showed signs of resilience as they were significantly more likely to be employed, had higher income, and experienced less stress but comparable social support. For both groups, higher stress and passive coping significantly predicted higher depression level. Total social support, active coping and younger age also significantly ameliorated depression for the native born. Among the various types of stress and social support, only family related sources were significant in predicting depression, indicating the impact of familism on Mexican Americans.

Migrants in a new destination are prone to vulnerabilities like financial difficulties, difficulty in adjustment to new ecological, socio-cultural and political contexts (Adhikari \& Gurung, 2009). Brusle (2008) claims that migrants adopt both coping strategies as well as accumulative strategies in managing such problems.

The results of research findings about return migration show that the reentry process is difficulter than entry to a foreign country.

Psychological counseling and guidance services are of much importance for abroad experienced students to adapt themselves to and interact with the Turkish society and the education system in a fitting way. In order to organize and maintain the psychological counseling and guidance services in the schools for the students who returned from abroad it is essential to determine their needs and problems.

The aim of this study was to analyze the problems of abroad experienced students after return from abroad and the coping strategy that they use for these problems.

The following questions will to be answered in this study:

1. What are the problems of abroad experienced students after return from abroad?

2. Do the coping strategies that are used by abroad experienced students for their

problems vary according to gender?

3. Do the coping strategies that are used by abroad experienced students for their problems vary according to age?

4. Do the coping strategies that are used by abroad experienced students for their problems vary according to the length of the period in which they lived abroad?

\section{Method}

\subsection{Sampling Participants}

The participants were 102 abroad experienced students (45 female; 57 male) studying in a university in Ankara Turkey who participated in the study as volunteers. Their ages range from 19 to 25 . Most of them lived 10 and more years abroad.

\subsection{Instruments of Data Collection}

Coping Strategy Scale and Personal Information Form that have been prepared by the researcher have been used for the subjects in order to determine the methods that are used to deal with the problems.

In the introduction part of the Coping Strategy Scale, the problem areas have been asked open ended to explain the problems that disturbed those most. Thus, the problem areas of the students have been determined through the content analyses of the problems written in the introduction of the Coping Strategy Scale.

Short descriptive information has been given below about the Coping Strategy Scale. In the research, coping strategies; the scale that has been developed by Amirkhan (1990) and adapted into Turkish by Aysan (2003) have been evaluated through the Coping Strategy Scale about which the validity and reliability work has been carried out. The Coping Strategy Scale has three sub- scales : problem solving, seeking social support and abstaining. Each sub-indicator is measured with 11 coping expressions and total number of the expressions in the indicator is 33 .

It has three subscales. The findings about the point invariability and work consistency of the sub-indicators of the Coping Strategy Indicator suggest that the scale is highly reliable (Aysan, 2003).

\subsection{Data Analysis}

Data has been analyzed at two stages. At the first stage, the most encountered problem areas have been determined. To this end, content analysis has been carried out. At the end of the analysis three categories have been formed in accordance with the content similarities of the problems described by the student. The following names have been given to these categories according to the contents of the problems forming the category:

1. Problems concerning the school life (26.5\%).

2. Problems concerning families and friends $(38,2 \%)$. 
3. Problems concerning the future life $(35,3 \%)$.

Each category can also be named as the "problem area".

At the second stage, analysis of data by t test, one-way analysis of variance (ANOVA) technique was used, after variance analysis the Scheffe test has been carried out determine whether the strategies that are adapted by abroad experienced students to cope with the three problem areas vary according to gender, age, the length of abroad period (variance analysis) and determine which group the difference results from when the impact is found considerable.

\section{Findings}

The findings of the study that has been carried out so as to determine the effects of some variables on the coping strategy that are used by abroad experienced students for the problems are given below:

As you see in the Table 1, the gender factor doesn't have an effect on the difference of the coping strategies of abroad experienced students $(\mathrm{p}>0.05)$

Table-1. Averages concerned with the genders of abroad experienced students and their coping strategies,means, standard deviations and results of the T-Test

\begin{tabular}{|c|c|c|c|c|c|}
\hline Coping Strategy & Gender & n & $\overline{\bar{X}}$ & s.d. & $\mathrm{t}$ \\
\hline \multirow[t]{2}{*}{ Social support } & Female & 45 & 22,682 &, 4158 & \multirow{2}{*}{44} \\
\hline & Male & 57 & 22,298 &, 4480 & \\
\hline \multirow[t]{2}{*}{ Problem solving } & Female & 45 & 23,056 & ,6137 & \multirow{2}{*}{$, 1,48$} \\
\hline & Male & 56 & 21,220 & ,6569 & \\
\hline \multirow[t]{2}{*}{ Abstaining } & Female & 45 & 17,293 &, 5428 & \multirow{2}{*}{$, 1,62$} \\
\hline & Male & 57 & 19,378 & ,7036 & \\
\hline
\end{tabular}

As you see in the Table 2 , the age factor doesn't have an effect on the difference of the coping strategies of abroad experienced students. $(\mathrm{p}>0.05)$.

Table-2. Averages concerned with the ages of abroad experienced students and their coping strategies, means, standard deviations and results of the variance analysis.

\begin{tabular}{c|c|c|c|c|c}
\hline Coping Strategy & Age & $\mathbf{n}$ & $\bar{X}$ & S.D. & t \\
\hline Social support & $19-21$ & 24 & 22,875 &, 4703 & \multirow{2}{*}{1,405} \\
\hline & $22-24$ & 26 & 22,978 &, 4519 & \\
\hline & 25 more & 31 & 21,387 &, 3612 & \multirow{2}{*}{$: 849$} \\
\hline Problem solving & Total & 101 & 22,465 &, 5949 &, 6611 \\
\hline & $19-21$ & 24 & 21,007 &, 6491 &, 6414 \\
\hline & $22-24$ & 46 & 21,793 &, 5597 & $: 395$ \\
\hline Abstaining & 25 more & 31 & 23,199 &, 5920 &, 7773 \\
\hline & Total & 101 & 22,038 &, 6440 & \\
\hline
\end{tabular}

As you see in the Table 3 and Table 4, the coping strategies of abroad experienced students vary according to the length of their abroad lives as far as the results of the variance analysis are concerned. $(p<$, o5) The Sheffe test has been carried out to understand the difference in the groups. The difference between the points given to the subindicator of the social support of the coping strategies is $\mathrm{p}<, 05$.

Table-3. Averages concerned with the length of abroad period of abroad experienced students and their coping strategies, means, standard deviations.

\begin{tabular}{c|c|c|c|c}
\hline Coping Strategy & Length of Abroad period & $\mathbf{n}$ & $\mathbf{x}$ & S.D. \\
\hline Social support & $1) 1-8$ years & 25 & 26,680 &, 3637 \\
\hline & $2) 9-17$ & 51 & 21,275 &, 3400 \\
\hline & $3) 18+$ more & 25 & 20,680 &, 3976 \\
\hline Problem solving & Total & 101 & 22,465 &, 4326 \\
\hline & $1) 1-8$ years & 25 & 16,700 &, 4273 \\
\hline & $2) 9-17$ & 50 & 25,100 &, 5768 \\
\hline & $3) 18+$ more & 26 & 21,282 &, 5832 \\
\hline & TOTAL & 101 & 22,038 &, 6414 \\
\hline Abstaining & $1) 1-8$ years & 25 & 18,982 &, 3030 \\
\hline & $2) 9-17$ & 50 & 16,400 &, 6637 \\
\hline Note: ${ }^{p}<0.05$ & $3) 18+$ more & 26 & 21,958 &, 7017 \\
\hline & Total & 101 & 18,470 &, 6440 \\
\hline
\end{tabular}

According to the results of the Scheffe test conducted, there is a difference between the group of 1-7 years, that of 9-17 years and that of 18 and more. 
Table-4. Results of the variance analysis concerned with the length of abroad period of abroad experienced students and their coping strategies.

\begin{tabular}{|c|c|c|c|c|c|c|c|}
\hline $\begin{array}{c}\text { Coping } \\
\text { Strategy }\end{array}$ & Variance Source & Sum of squares & df & Mean Square & $\mathbf{F}$ & Sig & Scheffe Test \\
\hline Social & Between groups & 5,961 & 2 & 2,980 & \multirow{3}{*}{22,908} & \multirow{3}{*}{1000} & 2-Jan \\
\hline \multirow[t]{2}{*}{ Support } & Within groups & 12,756 & 98 &, 130 & & & 3-Jan \\
\hline & TOTAL & 18,711 & 100 & & & & \\
\hline Problem & Between groups & 11,960 & 2 & 5,980 & \multirow{3}{*}{20,080} & \multirow{3}{*}{1000} & 2-Jan \\
\hline \multirow[t]{2}{*}{ Solving } & Within groups & 29,185 & 98 & ,298 & & & 3-Jan \\
\hline & TOTAL & 41,145 & 100 & & & & $3-\mathrm{Feb}$ \\
\hline \multirow[t]{3}{*}{ Abstaining } & Between groups & 5,371 & 2 & 2,686 & \multirow{3}{*}{7,291} & \multirow{3}{*}{1000} & \multirow{3}{*}{ 3-Feb } \\
\hline & Within groups & 36,099 & 98 & ,368 & & & \\
\hline & TOTAL & 41,470 & 100 & & & & \\
\hline
\end{tabular}

The difference between the points given to the sub-indicator of the problem solving of the coping strategies is $\mathrm{p}<, 05$. According to the results of the Scheffe test conducted, there is a difference between the group of 1-7 years, that of 9-17 years and that of 18 and more.

\section{Discussion}

In this study, the coping strategies of abroad experienced students who returned from abroad to Turkey have been examined according to the factors such as gender, age and length of the abroad period.

The findings of the research show that $26,5 \%$ of abroad experienced students have problems with the school, $38,2 \%$ of them problems with families and friends and $35,3 \%$ of them problems with the future life. These findings support the conclusions of Tam and Lam (2005) and Seiffge-Krenke (1990) 's work and Razum et al. (2005).Findings show that among migrants, future-related problems are often perceived as the most stressful.Being different from other studies (Tam \& Lam, 2005) which were carried with the return migrants, the findings of the present study show that gender and age do not have a determining role on the selection of the coping strategies used by abroad experienced students.

According to the findings, $17,6 \%$ of the students returned to Turkey in $1997 ; 16,7 \%$ of them in $1998 ; 15,7 \%$ of them in $1995 ; 13,7 \%$ of them in $1994,8,8 \%$ of them in 2000 and the others returned after 1985 . Research findings show that the length of the abroad life has a determining role on the selection of the coping strategies adopted by them.

Along with this, findings also show that the abroad experienced students who lived 1-8 years abroad, prefer the social support seeking strategy among the sub-indicators of the coping strategies; the abroad experienced students who lived abroad for 9-17 years prefer the problem solving strategy among the sub-indicators of the coping strategies and those who lived abroad for 18 or more years prefer the abstaining strategy among the sub-indicators of the coping strategies. These findings support the conclusions of Magnusson (1981) and Doğan (1988).

A similar observation was reported in Wong (1999) study on Chinese youth in Canada in which the greater the acculturation, the more likely the youth were to have problems.

Tam and Lam (2005) reported that migrants who had lived in Hong Kong for a longer period of time resembled local-born youth in that they had lower self-esteem and higher incidence of delinquent behavior than the recent arrivals, indicating negative assimilation to the new social environment.

It has been seen in this study that, which lived abroad for a long time have more adaptation problems after return to homeland.

\section{Conclusion}

When examining the findings of the research in general, the following results and recommendations have been determined:

1. It can be suggested that although a long time has passed since the abroad experienced students returned to Turkey, they are still not adapted to the new environment and affected negatively by it.

2. In addition to the problems of abroad experienced students with the school life and their future life, they are faced with problems mostly in their family and friendship relations. This result is also consistent with the research findings in the literature.

3. It is recommended that this research be made more widely and on more students who experienced abroad life. In such a research, half-structured questions allowing the students to describe their problems can be used.

4. The psychological counseling and guidance services should be organized very well to help; experienced advisers who have inter-cultural counseling abilities should be employed in these units. Results of the study are important for effective guidance by psychological counseling services.

To this end, Psychological Counseling and Guidance divisions in the universities put "Inter-cultural Counseling" lessons in the graduate, post-graduate and doctorate studies.

5. Experimental researches on the effectiveness of techniques such as group guidance and behavior shaping should be made to help to solve the adaptation problems of abroad experienced students within the shortest time possible.

\section{References}

Adhikari, J., \& Gurung, G. (2009). Migration between Nepal and India: Security and livelihood concerns. Kathmandu: Nepal Institute of Development Studies.

Amirkhan, J. (1990). A factor analytically derived measure of coping: The coping strategy indicator. Journal of Personality and Social Psychology, 59(5), 1066-1074. Available at: https://doi.org/10.1037/0022-3514.59.5.1066.

Aysan, F. (2003). Creating the Turkish version of the coping strategy scale (Turkish Version of Coping Strategy Indicator). Ege Journal of Education, 1(3), 123-132.

Bennett, J. W., McKnight, R. K., \& Passin, H. (1958). In search of identity: The Japanese overseas scholars in Americe andjapan. Minneapolis: University of Minnesota Press. 
Brusle, T. (2008). Choosing a destination and work: Migration strategies of Nepalese workers in Uttarkhand, North India. Mountain Research and Development, 28(3/4), 240-247.

Cetïn, T., \& Ercan, L. (2008). University students returning from abroad investigation of problems. (An Analysis of the Problems Faced by Turkish Students after Return Migration). Journal of Turkish World Studies, 8(2), 65-80.

Christofi, V., \& Thompson, C. (2007). You cannot go home again: A phenomenological investigation of returning to the sojourn country after studying abroad. Journal of Counseling छ Development, 85(1), 53-63. Available at: https://doi.org/10.1002/j.15566678.2007.tb00444.x.

Doğan, S. (1988). For high school students who had and didn't live abroad problems. Unpublished PhD Thesis. H.Ü. Institute of Social Sciences. Ankara.

Esentürk-Ercan, L. (2004). The return migration of Turkish youth to their homeland - one empirical study of reasons for migration, the current situation and future perspectives of the second generation. The Unifying of Cultures, Section: Pedagogy / Education, No. 15 , TRANS Internet Journal.

Federal Statistical Office. (2001). Statistical yearbook for the federal republic of Germany 2001. Statistisches Bundesamt (Federal Statistical Office), Vertriebspartner (Distribution Partner): SFG Servicecenter Fachverlage Part of the Elsevier Group, Wiesbaden; Internet. Retrieved from: www.destatis.de.

Gama, E. M., \& Pedersen, P. (1977). Readjustment problems of Brazilian returnees from graduate studies in the United States. International Journal of Intercultural Relations, 1(4), 46-59. Available at: https://doi.org/10.1016/0147-1767(77)90031-1.

Gullahorn, J. T., \& Gullahorn, J. E. (1963). An extension of the U-curve hypothesis 1. Journal of Social Issues, 19(3), 33-47. Available at: https://doi.org/10.1111/j.1540-4560.1963.tbo0447.x.

Kung, W. W., Castaneda, I., \& Lee, P.-J. (2004). Stress, social support, and coping as predictors of depression level: Difference between native-born and immigrant Mexican Americans. Journal of Immigrant $\Xi^{2}$ Refugee Services, 1(3-4), $61-80$.

Kuruuzüm, A. (2002). A field on the adaptation problems of the children of workers who make a absolute return. Akdeniz Univ.I.B.F Journal, 2(3), 102-113.

Magnusson, K. (1981). Between two cultures"A study of attitudes and behaviour of Yugoslav youth in Sweden”I.Municio (Ed.), Family and Position in the Swedish Society (pp. 61-62). SPLIT-Report, II, Stockholm.

Martin, J. N. (1984). The intercultural reentry: Conceptualization and directions for future research. International Journal of Intercultural Relations, 8(2), 115-134. Available at: https://doi.org/10.1016/0147-1767(84)90035-x.

Mudra, G. (2008). A study of perceived stress, impact and coping strategies. The International Journal of Interdisciplinary Social Sciences, 2(4), 325-334.

Razum, O., Sahin-Hodoglugil, N. N., \& Polit, K. (2005). Health, wealth or family ties? Why Turkish work migrants return from Germany. Journal of Ethnic and Migration Studies, 31(4), 719-739.

Rohrlich, B. F., \& Martin, J. N. (1991). Host country and reentry adjustment of student sojourners. International Journal of Intercultural Relations, 15(2), 163-182.

Sahin, C. (2001). A concerning the effect of migration abroad on the psychological health of the individual. Review G. U.GEF Magazine, 21(2), $57-67$.

Seiffge-Krenke, I. (1990). Coping style in adolescence. Journal of Cross-Cultural Psychology, 21(3), 351-377.

Tam, V. C.-W., \& Lam, R. S.-Y. (2005). Stress and coping among migrant and local-born adolescents in Hong Kong. Youth \& Society, 36(3), 312-332. Available at: https://doi.org/10.1177/0044118x04265092.

Wong, S. K. (1999). Acculturation, peer relations, and delinquent behavior of Chinese-Canadian youth. Adolescence, $34(133), 107-119$.

Yasa, I. (1979). Returning workers and social change. Ankara: TODAİE Publications. 